\title{
Views of second year nursing students on impediments to safety in the clinical setting: Q-methodology
}

\author{
Phyllis Montgomery ${ }^{1}$, Sharolyn Mossey ${ }^{1}$, Laura Killam² \\ 1. School of Nursing, Laurentian University, Ontario, Canada. 2. School of Health Sciences and Emergency Services, \\ Cambrian College of Applied Arts and Technology, Canada.
}

Correspondence: Sharolyn Mossey. Address: School of Nursing, Laurentian University, Ramsey Lake Road, Sudbury, Ontario, Canada, P3E 2C6. Email: smossey@laurentian.ca.

Received: September 27, 2012 Accepted: October 15, 2012

DOI : $10.5430 /$ jnep.v3n8p1

URL: http://dx.doi.org/10.5430/jnep.v3n8p1

Online Published: January 22, 2013

\section{Abstract}

Background: Little is known about novice students' perspectives of safety in clinical learning. This gap prevents a comprehensive understanding of their efforts to demonstrate clinical competence while securing safety for stakeholders in increasing complex practice environments. The purpose of this study was to describe impediments to safe clinical learning as perceived by second year students enrolled in a baccalaureate nursing program.

Methods: Q-methodology was used to systematically elicit multiple viewpoints about unsafe clinical learning circumstances. Across two program sites in northern Ontario, Canada, 73 second year students sorted 43 theoretical statement cards identifying unsafe clinical practices and situations. Centroid factor analysis and varimax rotation yielded correlations between participants who held similar and different viewpoints about impediments to safety in clinical learning.

Results: Three discrete perspectives and one consensus perspective constituted second year students' description of unsafe clinical circumstances. The discrete viewpoints were unprepared for role enactment, unsupported learning, and breached standards. There was consensus that a failure to demonstrate patient protection compromised clinical safety. The findings characterized unsafe clinical milieus as a combination of student, educator and programmatic accountability issues.

Conclusions: The shared perspectives of novice learners call attention to student preparedness, learning support and adherence to disciplinary standards. Educators and clinicians are compelled to address these issues for the development of conscientious novices within a culture of safety.

\section{Key words}

Nursing education, Q-methodology, Safety, Clinical learning, Students’ perspective

\section{I ntroduction}

Patients, practitioners, practice organizations, educational programs, and healthcare systems share the responsibility for safety in healthcare. These networks of safety stakeholders individually, and more recently collectively, engage in 
proactive strategies to safeguard patients ${ }^{[1,2]}$. Given that nursing students interface with patients during their formative years of development, several undergraduate nursing curricula are being redesigned to integrate safety content and experiential learning specific for the transition of novices into the complex practice realities of healthcare ${ }^{[3,4]}$. This includes general recommendations for curricular structures to build safety competencies. The specificity of safety content, teaching, and evaluative strategies is emerging ${ }^{[5]}$. As such, students are a vested stakeholder in the preservation of clinical safety.

\section{Background}

The following literature review presents evidence about the learning and clinical safety of second year nursing students. This body of evidence is predominantly exploratory or descriptive in nature. Collectively, these studies suggest the centrality of simultaneous development of novice professional competency and preservation of patient safety. Three general foci particular to second year nursing students include student stress, learning dynamics, and programmatic support for safety in learning. It is noteworthy that some of the selected reports in this review integrate other levels of students. Where this occurred, to the extent possible, the composition of the sample is described.

\section{Student stress}

Research consistently supports stress as an inherent aspect of clinical nursing learning and performance. Jimenez and associates ${ }^{[6]}$ described the nature of stress and its effect on health in a sample of first, second and third year nursing students during clinical practice. Regardless of year in the program, students identify three sources of stress. The sources included witnessing patient suffering, being unable to engage with patients or health care providers, and lacking clinical competency. Both first and second year students reported clinical stressors as more anxiety- provoking than academic and non-academic stressors. In particular, second year students found clinical assignments as significantly more stressful in comparison to first year students. Second and third year students identified clinical learning environments as more stressful than first year students. Overall, second year students reported more psychological symptoms than students in the other two years of the nursing program.

There is research suggesting that anxiety, in response to stress, may become a learning impediment. Melincavage ${ }^{[7]}$ investigated student nurses' perception of anxiety-producing clinical situations. She described her study sample as students who completed at least one clinical experience. Students became anxious when their expectation to skillfully perform nursing acts learned in the academic setting was not met. Further, Melincavage ${ }^{[7]}$ reported students had increased emotional vulnerability in the presence of negative interactions with fellow students, educators, staff nurses, and other health professionals. Anthony and Yastik ${ }^{[8]}$ also described the emotional distress novice students experienced as witnesses to incivility in their learning environments. In such contexts, students were dismissed or became a target of others' hostility. In response to humiliation, powerlessness, displacement, second year students experienced distress in how best to accommodate to such learning environments ${ }^{[9]}$.

\section{Learning dynamics}

While it is suggested that the primary responsibility for ensuring safety in learning lies with educational institutions, some authors suggested that practice settings as well as educators also have an impact on clinical safety ${ }^{[10,11]}$. Vaismoradi and associates ${ }^{[12]}$ reported that students want to protect patients during their clinical learning. They contended that students were most satisfied with their transition into clinical when they had been exposed to practical rather than theoretical knowledge. Students described the importance of learning patient safety from a practical orientation so that they could purposefully intervene with their assigned patients. Without meaningful clinical learning opportunities, second year students may develop a sense of apathy and disconnectedness ${ }^{[13]}$. 
To develop students' abilities and responsibilities as patient safety advocates, Debourgh ${ }^{[1]}$ raised concerns about the selection of appropriate placements. There is, however, contradictory evidence concerning the effects of inpatient or community settings on students' attitudes, comfort level and performance ${ }^{[14,15]}$. Happell ${ }^{[16]}$, in a descriptive survey, measured students' attitudes about and satisfaction with their mental health learning placements. She reported that community-based students had significantly higher satisfaction scores in comparison to students in inpatient-based psychiatric services. She further noted that, regardless of the setting, there was a significant relationship between time spend with the educator and positive learning experience. Wolff Staalvik and associates ${ }^{[17]}$ also examined first, second and third year students' satisfaction with their clinical learning environments. Although nursing home placement students perceived staff as more welcoming than hospital staff, students preferred participation in acute over non-acute care practice.

Henderson, Happell \& Martin ${ }^{[14]}$ explored the influence of mental health learning activities on second year nursing students' self-reported knowledge, skills and attitudes. Theses researchers reported that students associate higher knowledge skills and attitudes with clinical rather than classroom experiences. Overall, students with greater theoretical knowledge had higher clinical knowledge and skills compared to those students who had limited theoretical exposure. They agree with the premise of students need time in transitioning knowledge for safe 'deliberate, conscientious practice, $^{[12]}$. Time offer opportunities for novice learners to engage in critical dialogue with educators about patient safety as lived.

To preserve patient safety with students new to clinical, their relationship with educators is salient. Guided learning through a supportive student-educator relationship fostered students' sense of belonging and confidence ${ }^{[18]}$. Gidman and associates ${ }^{[19]}$ investigated novice and senior undergraduate nursing students' perceptions of clinical support. They reported that nursing students, regardless of year in program, expected enthusiastic, approachable and competent educators. Overall, students identified educators as their main source of support during their transition from classroom to clinical. In comparison to senior students, novice students characterized a supportive educator as providing relevant content- and skill-based learning activities pre-clinical. Baxter and Rideout ${ }^{[20]}$ reported that the greatest learning challenge for second year students is clinical decision making. Without theoretical knowledge or informed clinical educators, students lacked confidence and struggled to understand an appropriate course of action when confronted by actual clinical situations. For second year students, competent educators demonstrated their praxis as well as provided constructive evaluative feedback to address their desire for becoming nurse ${ }^{[21]}$.

\section{Program support}

At the educator level, there is research addressing second year students' development of clinical reasoning relative to various clinical teaching approaches. Problem-based learning was specifically identified as one strategy to bridge the theory/practice gap, and ultimately, promote safety ${ }^{[22,23]}$. Larue ${ }^{[23]}$ described the learning and teaching strategies observed in the tutorial work groups of second year students. The most frequent cognitive learning strategies of the students were repetition, elaboration, organization, generalization and discrimination. To reinforce students' learning, the tutors typically engaged in questioning, reasoning and voicing doubts. Problem-based learning approaches were also attributed to second and third year students' development of responsibility for their learning and professional relations with their educators ${ }^{[24]}$.

Simulation was another strategy to reduce errors linked to second year students' skill-based performances. Brimble ${ }^{\text {[25] }}$ explored the learning needs of second year students with regards to caring for paediatric patients. Using simulation, students had immediate feedback regarding their performance. This assisted them in refining their practice competencies. Post-simulation, students expressed less concern about making mistakes, being anxious and being evaluated in the actual clinical environment. Prescott and Garside ${ }^{[26]}$ also reported that second year simulation exercises developed students' performance confidence as well as their clinical judgement abilities. In part, this growth was attributed to the less 
threatening learning environment of the lab in comparison to that of the clinical setting ${ }^{[13,27]}$. In particular to the development of competencies related to medication administration, second year students preferred being evaluated with clinically-relevant scenarios. That is, $80 \%$ of students exposed to written, visual, hands-on learning activities that integrate elements of 'real' clinical cases reported greater confidence in their numeracy skills and stress reduction ${ }^{[28]}$.

At a system level, Debourgh ${ }^{[1]}$ evaluated an academic and service partnership model to promote safety in learning for students enrolled in the third semester of a four year undergraduate program. This model provides an infrastructure for increasing students' and clinicians' knowledge of the professional accountabilities for patient safety and quality outcomes. A key strategy of this model, known as the synergy partnership, is perfection-for, -in, and -on action guided by content and process resources. Through continuous attention to students' internal thought processes and modeling of assertive communication, safety and quality issues are reinforced. A proposed result is student confidence in their emerging knowledge and skills. Debourgh ${ }^{[1]}$ found that this approach increased novice students' awareness of safety knowledge and their involvement in positive patient outcomes.

Less is known, however, about novice students' perspectives of safety in clinical learning. This gap prevents a comprehensive understanding of their efforts to develop and demonstrate clinical competence in increasing complex practice environments. The purpose of this study was to describe impediments to safe clinical learning as perceived by second year students enrolled in a baccalaureate nursing program.

\section{Methods}

\subsection{Design}

The design of this study was Q-methodology. It integrates the strengths both qualitative and quantitative methods to generate a subjective orientation about a multi-faceted phenomenon ${ }^{[29]}$. Q-methodology involves the ranking of a sample of statements to produce a Q-sort, a conceptual representation of the views of a group of participants ${ }^{[30-32]}$. This method makes evident "those statements that are most representative of, are indifferent to, or most unrepresentative of" [33, p. 175] the topic of inquiry. Based on statistically significant patterns of similarities and differences, sub-groups of attitudes, beliefs, and perceptions are identifiable ${ }^{[29,34]}$.

Q-methodology is described in the nursing literature ${ }^{[30,34,35]}$. This method was used to differentiate categories of healthcare students to assist with curriculum development ${ }^{[36]}$. Also, it was used to describe nursing faculty's viewpoints about collaborative baccalaureate education ${ }^{[37]}$. Since Q-methodology reveals the underexplored, heterogeneous nature of a study's phenomenon ${ }^{[33]}$, it is suitable for this study's objective to describe theoretically divergent perspectives of students on impediments to safe clinical learning.

\subsection{Setting and sample}

The setting for the study was a baccalaureate nursing program grounded in the humanistic educative paradigm. The program is offered through a collaborative partnership between an university and community colleges in Ontario, Canada. Before entry into the second year of the program, students have completed 26 weeks of classroom and clinical learning experiences that blend foundational ontological, epistemological, and praxis components of nursing. A second year program objective is upholding clinical safety while developing students' cognitive, affective, and practice competencies through increasing complex patient assignments. Second year clinical experiences involve the provision of nursing care of individuals and their families across the continuum of care. Using purposive sampling, all second year nursing students enrolled at a single site $(n=75)$ within the collaboration were invited to participate in the study. A total of 73 students submit completed Q-sorts. This study received ethical approval from the participating educational institutions. 


\subsection{Data collection}

Fundamental to Q-methodology is the creation of a concourse, a collection of statements about the phenomenon of interest. The concourse developed for this study involved two sequential stages. The first stage was the creation of an initial list of statements specific to unsafe practices in student-based clinical learning. This was achieved by extracting applicable statements from published theoretical and empirical literature. These statements were added to an existing concourse used in an earlier study about safety and fourth year nursing students ${ }^{[39]}$. The combined list yielded a total of 232 statements. In the second stage, each author independently reviewed the list to clarify the semantics of each statement and eliminate duplications. This process resulted in a modified list of 63 statements. Then, seven consultants were invited to examine the list for relevancy, conceptual clarity, parsimony and content validity. The consultants included two undergraduate nursing students not involved as participants in this study, two graduate nursing students, an experienced nurse clinician and educator, and two faculty members. Based on their recommendations and through consensus, the finalized concourse included 43 descriptive statements about impediments to safe clinical learning. These two stages were undertaken for the purposes of establishing content, face and Q-sorting validity as outlined by Akhtar-Danesh and colleagues ${ }^{[34]}$. The composite reliabilities in this study ranged from 0.97 to 0.99 . These values exceed the recommended $0.95^{[39]}$.

Consenting students participated in the Q-sort activity led by one of the authors. Individual students were provided with 43 cards and a blank template. Each double-sided card contained a single typed statement from the concourse with a randomly assigned number on the reverse side. The template contained 43 spaces arranged as an inverted pyramid with the two endpoints labelled as Most Agree (+5) and Most Disagree (-5). Participants were instructed to consider the extent to which they agreed that each statement was a variable in response to the question, "It is most unsafe in the clinical setting when ...” Then, each participant identified the final ranking of each statement by recording its assigned number on the blank template.

\subsection{Data analysis}

The 73 completed Q-sort templates were entered into the statistical program known as PQ Method 2.11 ${ }^{[40]}$. This program performs centroid factor analysis and varimax rotation. This analysis is a 'by-participant' factor analysis, identifying correlations between those who share common and divergent viewpoints ${ }^{[34]}$. Three discrete viewpoints and one consensus viewpoint were generated. A discrete viewpoint represents a statistically significant set of statements shared by a subgroup of participants; a 'like-minded-ness' among students with regards to when it is most unsafe in clinical learning. The consensus viewpoint indicates statistically significant similarities in the ranking of statements across the discrete viewpoints. Within this study, the commonalities and differences among discrete and consensus viewpoints were examined and assigned initial conceptual descriptive label. These initial labels were further refined through concurrent content, structural and interpretative analysis.

\section{Results}

The Q-sorts of 49 of the 73 second year students significantly loaded on three discrete viewpoints and one consensus viewpoint. The three discrete viewpoints were labelled unprepared for role enactment, unsupported learning, and breached standards. Collectively, these viewpoints described the behavioural, cognitive, attitudinal, and contextual issues that disrupt safe clinical learning. The consensus viewpoint was labelled patient protection. It identified a shared understanding that an impaired student-educator partnerships impedes patient safety. The student-educator partnership necessitated a mutual commitment to guide learning for the purposes of responsible development and engenderment of safety.

\section{Viewpoint 1: Unprepared for Role Enactment}

Eleven second year students shared the first viewpoint, unprepared for role enactment. It was comprised of 17 distinguishing statements (see Table 1). For this group of students, it was viewed as most unsafe when the student with 
knowledge deficits $(5 /+3)$ does not accurately report patient status $(7 /+4)$ or perform care $(8 /+3)$. Within this context, the clinical educator was disadvantaged by a lack of pedagogical guidelines for appropriate intervention $(33 /+2)$ to preserve safety. Not only was the student-patient relationship threatened by a rushed approach to care $(9 /+2)$ and absence of patient-centeredness $(19 /+2,20 /+2)$, it also predisposed the student to unsafe practice. The gap between sequential clinical placements further impeded safe and authentic care $(26 /+2)$. To a lesser extent, isolated decision making $(2 /+1)$ and lack of educator role-modelling $(38 /+1)$ potentiated unsafe clinical practice risks. The educator's inability to demonstrate role competence (22/0) and maintain student practice boundaries (27/0) neither impeded nor facilitated clinical safety. Participants ranked ineffectual student communication (14/-3), lack of program policy enforcement by the educator ${ }^{\text {[41] }}$, and lack of educator guidance (21/-2) as elements of the student-educator dyad that had little impact on clinical safety. Of least importance in ensuring safe clinical practice was avoidance of being overwhelmed either by course (25/-4) or role expectations (35/-3).

Table 1. Unprepared for Role Enactment: Distinguishing Statements

\begin{tabular}{|c|c|c|c|c|}
\hline \multicolumn{2}{|c|}{ Numbered Statements } & \multicolumn{3}{|c|}{$\begin{array}{l}\text { Statement rankings across discrete } \\
\text { viewpoints }\end{array}$} \\
\hline & & \multirow{2}{*}{$\begin{array}{l}\text { View } 1 \\
+4\end{array}$} & \multirow{2}{*}{$\begin{array}{l}\text { View } 2 \\
+3\end{array}$} & \multirow{2}{*}{$\begin{array}{ll}\text { View } 3 \\
+3\end{array}$} \\
\hline 7 & The student does not report changing patient conditions & & & \\
\hline 8 & $\begin{array}{l}\text { The student fails to perform care consistent with clinical guidelines and } \\
\text { standard procedures (hand washing; confidentiality) }\end{array}$ & +3 & +2 & 2 \\
\hline 5 & The student lacks the knowledge needed to assume care of assigned patients & +3 & +1 & 2 \\
\hline 3 & $\begin{array}{l}\text { There are no clear guidelines for how to deal with specific behaviours in the } \\
\text { clinical setting (when to fail someone) }\end{array}$ & +2 & -3 & -3 \\
\hline 9 & The student rushes through care & +2 & +1 & +1 \\
\hline 9 & $\begin{array}{l}\text { The student practices with impaired cognition (due to stress, drugs, alcohol, } \\
\text { or lack of sleep) }\end{array}$ & +2 & +4 & +4 \\
\hline 20 & The student does not demonstrate patient-centeredness (e. g. caring) & +2 & 0 & 0 \\
\hline 26 & The student has a large gap in time between practice placements & +2 & -3 & -1 \\
\hline 2 & $\begin{array}{l}\text { The student makes independent clinical decisions beyond his/her } \\
\text { competency }\end{array}$ & +1 & +3 & +3 \\
\hline 38 & The clinical educator does not role model established nursing standards & +1 & +2 & -1 \\
\hline 22 & The clinical educator demonstrates lack of competence in his/her role & 0 & +4 & +2 \\
\hline 27 & The clinical educator encourages students to do things beyond their scope & 0 & +2 & +3 \\
\hline 21 & The clinical educator does not appropriately guide student practice & -2 & +1 & 0 \\
\hline 31 & The clinical educator does not enforce clinical program policies & -2 & 0 & 0 \\
\hline 14 & The student has difficulty communicating (verbally or non-verbally) & -3 & 0 & 0 \\
\hline 35 & The clinical educator is overwhelmed by role expectations & -3 & 0 & 0 \\
\hline 25 & The student feels overwhelmed by course requirements & -4 & -5 & -1 \\
\hline
\end{tabular}

\section{Viewpoint 2: Unsupported Learning}

Nine students supported the second viewpoint, labelled unsupported learning. It was comprised of 11 distinguishing statements about the importance of guided student learning for safety (see Table 2). Perceived deficits in the educator's capacity to appropriately guide student learning were highly ranked in this perspective $(22 /+4,27 /+2,38 /+2)$. In this context, the educator's guidance was disregarded $(3 /+1)$. Exacerbating the educator's failure to support safe learning was the student's lack of preparatory knowledge $(5 /+1)$. Those statements perceived to have little impact on learning were independent student practices inclusive of care documentation (13/-1) and patient interaction (15/-2). Program impediments such as the schedule of clinical rotation (26/-3) and formative evaluations (23/-3) were negatively ranked. The statements considered to have the least importance were student's affective responses to learning (25/-5, 39/-4). 
Table 2. Unsupported Learning: Distinguishing Statements

\begin{tabular}{|c|c|c|c|c|}
\hline \multirow{2}{*}{\multicolumn{2}{|c|}{ Numbered statements }} & \multicolumn{3}{|c|}{ Statement rankings across discrete viewpoints } \\
\hline & & \multirow{2}{*}{$\begin{array}{l}\text { View } 1 \\
0\end{array}$} & \multirow{2}{*}{$\begin{array}{l}\text { View } 2 \\
+4\end{array}$} & \multirow{2}{*}{$\begin{array}{l}\text { View } 3 \\
+2\end{array}$} \\
\hline 22 & The clinical educator demonstrates lack of competence in his/her role & & & \\
\hline 27 & $\begin{array}{l}\text { The clinical educator encourages students to do things beyond their } \\
\text { scope }\end{array}$ & 0 & +2 & +3 \\
\hline 38 & The clinical educator does not role model established nursing standards & +1 & +2 & -1 \\
\hline 5 & $\begin{array}{l}\text { The student lacks the knowledge needed to assume care of assigned } \\
\text { patients }\end{array}$ & +3 & +1 & +2 \\
\hline 3 & The student does not consider the guidance of the clinical educator & -2 & +1 & -1 \\
\hline 13 & $\begin{array}{l}\text { The student does not provide accurate, relevant and timely } \\
\text { documentation of client care }\end{array}$ & +1 & -1 & +1 \\
\hline 15 & The student avoids interacting with the patient & +1 & -2 & +1 \\
\hline 26 & The student has a large gap in time between practice placements & +2 & -3 & -1 \\
\hline 23 & The student does not have access to ongoing performance feedback & -2 & -3 & -2 \\
\hline 39 & The student responds defensively to constructive feedback & -1 & -4 & -2 \\
\hline 25 & The student feels overwhelmed by course requirements & -4 & -5 & -1 \\
\hline
\end{tabular}

\section{Viewpoint 3: Breached Standards}

Table 3. Breached Standards: Distinguishing Statements

\begin{tabular}{|c|c|c|c|c|}
\hline \multirow{2}{*}{\multicolumn{2}{|c|}{ Numbered statements }} & \multicolumn{3}{|c|}{ Statement rankings across discrete viewpoints } \\
\hline & & \multirow{2}{*}{$\begin{array}{l}\text { View } 1 \\
+3\end{array}$} & \multirow{2}{*}{$\begin{array}{l}\text { View } 2 \\
+2\end{array}$} & \multirow{2}{*}{$\begin{array}{l}\text { View } 3 \\
+5\end{array}$} \\
\hline 1 & The student practices outside of his/her scope & & & \\
\hline 27 & $\begin{array}{l}\text { The clinical educator encourages students to do things beyond their } \\
\text { scope }\end{array}$ & +5 & +5 & +3 \\
\hline 6 & $\begin{array}{l}\text { The student is dishonest (makes up assessment data, covers up mistakes } \\
\text { or hides their lack of knowledge) }\end{array}$ & 0 & +2 & +3 \\
\hline 5 & $\begin{array}{l}\text { The student lacks the knowledge needed to assume care of assigned } \\
\text { patients }\end{array}$ & +3 & +1 & +2 \\
\hline 22 & The clinical educator demonstrates lack of competence in his/her role & +3 & +3 & +2 \\
\hline 24 & $\begin{array}{l}\text { The student is evaluated as successful despite a pattern of unmet } \\
\text { clinical expectations }\end{array}$ & 0 & +4 & +2 \\
\hline 10 & The student does not respect the rights of patients & 0 & -2 & +2 \\
\hline 40 & $\begin{array}{l}\text { The student is taught to cut corners or guided to do things differently } \\
\text { than what was taught in school }\end{array}$ & 0 & -1 & +1 \\
\hline 26 & The student has a large gap in time between practice placements & +2 & -3 & -1 \\
\hline 25 & The student feels overwhelmed by course requirements & +1 & +2 & -1 \\
\hline 38 & The clinical educator does not role model established nursing standards & -4 & -5 & -1 \\
\hline 42 & $\begin{array}{l}\text { The clinical educator does not set clear expectations with students at the } \\
\text { beginning or and throughout the placement }\end{array}$ & 0 & +1 & -2 \\
\hline 36 & $\begin{array}{l}\text { The clinical educator is unable to establish and maintain a positive } \\
\text { learning environment }\end{array}$ & -1 & 0 & -3 \\
\hline 41 & $\begin{array}{l}\text { The clinical educator does not provide constructive feedback in a } \\
\text { confidential manner }\end{array}$ & -1 & -1 & -4 \\
\hline 32 & $\begin{array}{l}\text { The clinical educator does not regularly document evaluations of the } \\
\text { student's performance }\end{array}$ & -1 & 0 & -4 \\
\hline
\end{tabular}

Twenty-nine students shared a common viewpoint that clinical safety was most compromised when educators and students failed to adhere to professional standards specific to the cognitive, ethical, and behavioral domains. This viewpoint, entitled, breached standards, was comprised of 15 distinguishing statements (see Table 3). Unknowing or intentional student practices beyond the scope of nursing $(1 /+5)$ and condoned by educators $(27 /+3)$ were indicative of high risk 
clinical situations. In addition, safety was threatened when students do not have requisite knowledge $(5 /+2)$ to assume patient care. It was riskier, however, when students wilfully concealed their knowledge deficits $(6 /+3)$ and by extension, masked their errors. Clinical educators failed to demonstrate their role competence (22/+2), uphold evaluative standards $(24 /+2)$, and integrate theory and practice $(40 /+1)$. Of less importance in maintaining standards was time between clinical placements (26/-1), manageable course expectations (25/-1), and failure of educators to role model (38/-1). Students recognized that fundamental patient rights were not respected (10/+2). The four statements identified as having the least impact for the preservation of standards related to educators' responsibilities of evaluation (32/-4, 41/-4, 42/-2) and the creation of a learning milieu (36/-3).

\section{Consensus viewpoint: Patient protection}

A number of statements received similar rankings across the three discrete viewpoints. This viewpoint was labelled, patient protection (see Table 4). It was perceived to be most unsafe when students did not protect patients from imminent or potential injury (18/rankings ranged from +4 to +3$)$. In part, a pattern of errors $(11 /$ rankings ranged from +2 to +1$)$ and an inability to modify care based on emerging patient needs $(17 /+1)$ created risky situations. The statement concerning the critical thinking abilities of the student (4) was consistently ranked as a neutral contributor to unsafe clinical practice. Also, the demeanour of the clinical educator received neutral to negative rankings across the three discrete viewpoints (43/rankings ranged from 0 to -1). From a program perspective, lack of consistency among clinical groups (34/ rankings ranged from -3 to -5 ) as well as receipt of unsuitable clinical assignments (28/ rankings ranged from -1 to -2$)$ were consistently negatively ranked. This suggested that these program issues had lesser impact on unsafe clinical situations.

Table 4. Patient Protection: Consensus Statements

\begin{tabular}{|c|c|c|c|c|}
\hline \multicolumn{2}{|c|}{ Numbered Statements } & \multirow{2}{*}{$\begin{array}{l}\text { View } 1 \\
+3\end{array}$} & \multirow{2}{*}{$\begin{array}{l}\text { View } 2 \\
+4\end{array}$} & \multirow{2}{*}{$\begin{array}{l}\text { View } 3 \\
+4\end{array}$} \\
\hline 18 & $\begin{array}{l}\text { The student does not protect patients from injury or potentially abusive } \\
\text { situations }\end{array}$ & & & \\
\hline 11 & The student demonstrates a pattern of errors (e. g. repeated mistakes) & +1 & +2 & +1 \\
\hline 17 & $\begin{array}{l}\text { The student is unable to modify care based on emerging patient } \\
\text { priorities }\end{array}$ & +1 & +1 & +1 \\
\hline 4 & $\begin{array}{l}\text { The student does not demonstrate critical thinking through the nursing } \\
\text { process }\end{array}$ & 0 & 0 & 0 \\
\hline 16 & $\begin{array}{l}\text { The student avoids consultation and collaboration with the clinical } \\
\text { educator and other health team members }\end{array}$ & -1 & -1 & 0 \\
\hline 43 & The student perceives the clinical educator as threatening & 0 & -1 & -1 \\
\hline 28 & $\begin{array}{l}\text { The clinical educator does not assign clinical learning experiences } \\
\text { consistent with student's learning needs }\end{array}$ & -2 & -2 & -1 \\
\hline 29 & $\begin{array}{l}\text { The clinical educator has not established a trusting relationship with } \\
\text { the student(s) }\end{array}$ & -3 & -1 & -2 \\
\hline 12 & The student is unable to control his/her nervousness & -3 & -2 & -2 \\
\hline 34 & $\begin{array}{l}\text { There are inconsistent expectations among clinical groups or faculty } \\
\text { (skill, workload, hours) }\end{array}$ & -5 & -3 & -3 \\
\hline 37 & The formal evaluation processes are unclear & -4 & -4 & -5 \\
\hline
\end{tabular}

\section{Discussion}

This study described second year nursing students' views of impediments to safe clinical learning. There was consensus that patient protection is fundamental to preserving clinical safety. This finding supports previous research that identified holistic patient well-being as central to undergraduate students' perspectives about safety ${ }^{[12,28]}$. The findings of this study also characterized unsafe clinical milieus by the absence of an overt focus on safety, appropriate professional development, and engaged competent educators. The conceptual labels assigned to these three perspectives included unprepared for role enactment, unsupported learning, and breached standards. 
Unprepared for role enactment suggested that novice practitioners' awareness of their responsibility for professional development and safety in the clinical practice setting. Unpreparedness, characterized by cognitive, behavioural and ethical deficits, had the potential to jeopardize patient protection. From this perspective, student preparedness involved individual accountability for learning guided by competent nurse educators within the context of programmatic and professional standards. Thereby, student preparation for practice must begin prior to entry into the clinical setting in order to preserve safety. Similarly, Gidman and associates ${ }^{[19]}$ reported that students were aware of their own learning responsibilities and the importance of guided skill acquisition, professionalism, and patient-centeredness.

Students' presence in the clinical setting suggested fulfillment of all preparatory obligations, and therefore, readiness for praxis. In this study's findings however, second year students perceived that some students were unprepared and consequently, not ready for practice. Such circumstances potentiated the risk for unsafe practice. Preparedness as demonstrated by "astute and early identification" ${ }^{[41 \mathrm{p} .22]}$ of changes in patients' health status is critical to safety and also, patients' well-being. The unprepared for role enactment viewpoint supported the need for nursing programs to standardized pre-clinical preparation followed by consistent evaluation of knowledge base, psychomotor skills, interactional abilities, and clinical decision-making ${ }^{[27,42]}$.

In the current study, clinical safety was considered to be further compromised when unprepared students were partnered with clinical educators who did not competently guide and evaluate their patient-centered learning. Patient management, critical reasoning and reflection for self-assessment is facilitated by capable educators ${ }^{[22]}$. The coming together of unprepared students in the educational process is a source of student anxiety ${ }^{[6,43]}$ and by extension, an impetus for unsafe clinical practices ${ }^{[4]}$. Sanctioned unpreparedness may negatively affect self-directed learning and meta-cognitive processes involved in the transition of novice student to nurse ${ }^{[44,45]}$.

The finding of unsupported learning suggested that novice practitioners rely on the involvement of the educator for their professional development and safety in clinical learning. The study participants acknowledged the hazards imposed by clinical educators perceived to be unable to facilitate their learning. Benner ${ }^{[41]}$ defined the critical role of the educator as:

helping novice students recognize the priorities and demands embedded in particular clinical situations so that they gain a sense of salience, that is, what must be attended to and addressed in relation to the significance an urgency in the particular clinical situation.

In the current study, students perceived it to be most unsafe when the clinical educator demonstrated a lack of role competence. Without overt evidence of the educator's competency, safety was jeopardized. In such circumstances, interactions between student and educator for clinical meaning-making were devalued. In turn, the risk for unsafe clinical learning experiences was potentiated. Clinical education devoid of credible learning exchanges impedes the translation of theoretical knowledge into skill 'know-how' ${ }^{[41,46]}$. The educator's purposeful demonstration of his/her competency establishes the foundation for supportive interactions with students. Such interactions offer the possibility of fostering receptivity, mutuality, situated cognition, self-improvement, reflection, and cooperation for learning and safety ${ }^{[21,41,44,47,48]}$. Sherwood and Drenkard ${ }^{[49]}$ suggested that some clinical educators may have been prepared prior to the contemporary focus on quality and safety competencies. Therefore, foundational and continuous professional development are required to augment their safety competencies as clinical educators ${ }^{[50]}$. The second year students description of unsupported learning supported the need for nursing programs to appraise their professional development initiatives available to their employed clinical educators.

Although not explored in this study, extending the educational partnership to include clinicians may support learning and safety in the clinical setting ${ }^{[5,51]}$. Clinicians' insider perspective regarding the realities of clinical practice is a valuable source of evaluative feedback regarding students' achievement of practice competencies ${ }^{[51]}$. Second year students' characterization of unsupported learning inferred broader programmatic issues related to support structures and policies. In addition to strengthening the support afforded to students in clinical learning, academic and service partnerships may 
preserve clinical safety. So that unsupported learning does not profilerate, nursing programs are encouraged to revisit clinical educator hiring criteria, clarify role expectations, articulate learning theory and evidence, match the educator's skill set with the learning milieu, and involve the educator in program planning.

Breached standards suggested that second year students have insight into academic and professional standards that impact learning and teaching. Their description of professional, ethical, behavioural and cognitive transgressions were counter to the standards within the discipline of nursing. The incongruence between expected and actual practice were observable, and possibly intentional in nature. To preserve safety, individuals must be accountable for maintaining the sanctity of established standards and addressing indicators of risk. In order to protect patients, it is necessary to differentiate between isolated errors, at-risk behaviours, and reckless practice ${ }^{[52]}$. A pattern of dishonesty, lack of integrity and patient disregard as described the second year students in this study was suggestive of an absence of responsibility and accountability in practice. Engagement in such practices boarders on reckless behaviour, an indicator of when it was most unsafe in clinical learning. The features of breached standards were similar to those reported by senior undergraduate nursing students and educators in relation to violated professional integrity ${ }^{[38]}$.

Regardless of semantics, the impediments described by second year students necessitate immediate efforts to hold student/ educator dyads accountable for contributing to high risk practice within a systems approach to safety management. As Dekker ${ }^{[52]}$ clarified,

We can create accountability not by blaming people, but by getting people actively involved in the creation of a better system to work in. Holding people accountable and blaming people are two quite different things. Blaming people may in fact make them...feel less compelled...to participate in improvement efforts. Blame-free...systems are not accountabilityfree systems... everybody can respond and take responsibility for doing something about the problem.

This author supported the likelihood of comprised clinical safety when individual practitioners, whether student or educator, were not held accountable for, nor took responsibility for, breaching academic and professional standards. A systems approach constituted by professional, ethical, behavioural, and cognitively-informed practices has the potential to engender a culture of safety for beginning nursing students.

\section{Conclusion}

This group of novice learners recognized the centrality of patient protection in clinical learning for safety. An educational culture constituted by student preparedness, learning support and adherence to disciplinary standards was foundational to promoting clinical safety and to developing conscientious students. Attending to the revealing perceptions of second year students concerning unsafe circumstances in clinical learning is congruent with being accountable to the creation and sustenance of a culture of safety.

\section{Competing interests}

The authors declare that they have no competing interest.

\section{Authors' contributions}

Each author has participation in the conception and methods of the study, involved in manuscript preparation and given final approval of the document.

\section{References}

[1] Debourgh GA. Synergy for patient safety and quality: academic and service partnerships to promote effective nurse education and clinical practice. Journal of Professional Nursing. 2012; 28(1): 48-61. PMid:22261605 http://dx.doi.org/10.1016/j.profnurs.2011.06.003 
[2] Palmieri PA, DeLucia PR, Peterson LT, Ott TE, and Green A. The anatomy and physiology of error in adverse health care events. In Advances in Health Care Management: Patient safety and Health Care Management. CT Savage \& EW Ford, eds. Bingley, UK: Emerald Group Publishing. 2008: 33-68. http://dx.doi.org/10.1016/S1474-8231(08)07003-1

[3] Barton AJ, Armstrong, G, Prheim, G, Gelmn SB, Andrus L. A national Delphi to determine developmental progression of quality and safety competencies in nursing education. Nursing Outlook. 2009; 57: 313-322. PMid:19942032 http://dx.doi.org/10.1016/j.outlook.2009.08.003

[4] Sherwood G. Integrating quality and safety science in nursing education and practice. Journal of Research in Nursing. 2011; 16(3): 226-240. http://dx.doi.org/10.1177/1744987111400960

[5] Cronenwett L, Sherwood G, Barnsteiner J, Disch J, Johnson J, Mitchell P, Taylor Sullivan, D, Warren J. Quality and safety education for nurses. Nursing Outlook. 2007; 55:122-131. PMid:17524799 http://dx.doi.org/10.1016/j.outlook.2007.02.006

[6] Jimenez C, Navia-Osorio PM, Dias CV. Stress and health in novice and experienced nursing students. Journal of Advanced Nursing. 2009; 66(2): 442-455. PMid:20423427 http://dx.doi.org/10.1111/j.1365-2648.2009.05183.x

[7] Melincavage SM. Student nurses' experiences of anxiety in the clinical setting. Nursing Education Today. 2011; 31: 785-789. PMid:21641701 http://dx.doi.org/10.1016/j.nedt.2011.05.007

[8] Anthony M, Yastik J. Nursing students' experiences with incivility in clinical education. Journal of Nursing Education. 2011; 50(3):140-144. PMid:21323254

[9] Curtis J, Bowen I, Reid A. You have no credibility: nursing students' experiences of horizontal violence. Nursing Education in Practice. 2007; 7: 156-163. PMid:17689439 http://dx.doi.org/10.1016/j.nepr.2006.06.002

[10] American Association of Colleges of Nursing. Hallmarks of quality and safety: recommended baccalaureate competencies and curricular guidelines to assure high quality and safe patient care. 2006. Available from: http://www.aacn.nche.edu/Education/PSHallmarks.htm

[11] Canadian Association of Schools of Nursing. Position statement: patient safety and nursing education. 2006. Available from: http://www.casn.ca/vm/newvisual/attachments/856/Media/PatientSaftyandNursingEducation.pdf

[12] Vaismoradi M, Salsali M, Marck P. Patient safety: nursing students' perspectives and the role of nursing education to provide safe care. International Nursing Review. 2011; 58: 434-442. PMid:22092321 http://dx.doi.org/10.1111/j.1466-7657.2011.00882.x

[13] Newton JM, Billett S, Jolly B, Ockerby CM. Lost in translation: barriers to learning in health professional clinical education. Learning in Health and Social Care. 2009; 8(4); 315-327. http://dx.doi.org/10.1111/j.1473-6861.2009.00229.x

[14] Henderson S, Happell B, Martin T. Impact of theory and clinical placement on undergraduate students' mental health nursing knowledge, skills, and attitudes. International Journal of Mental Health Nursing. 2007; 16: 116-125. PMid:17348962 http://dx.doi.org/10.1111/j.1447-0349.2007.00454.x

[15] Perese E. Undergraduates' perceptions of their psychiatric practicum: positive and negative factors in inpatient and community experience. Journal of Nursing Education. 1996; 35(6): 281-285. PMid:8877831

[16] Happell B. In search of a positive clinical experience. Mental Health Practice. 2008; 11(9): 26-31.

[17] Skaalvik MW, Normann HK, Henriksen N. Clinical learning environment and supervision: experiences of Norwegian nursing students - a questionnaire survey. Journal of Clinical Nursing. 2011; 20: 2294-2304. PMid:21752120 http://dx.doi.org/10.1111/j.1365-2702.2011.03727.x

[18] Koontz AM, Mallory JL, Burns JA, Chapman S. Staff students and students: the good, the bad, and the ugly. MEDSURG Nursing. 2010; 19(4): 240-246. PMid:20860251

[19] Gidman J, McIntosh A, Melling K, Smith D. Student perceptions of support in practice. Nursing Education in Practice. 2011 ; 11: $351-355$. PMid:21458375 http://dx.doi.org/10.1016/j.nepr.2011.03.005

[20] Baxter P. Rideout E. Second-year baccalaureate nursing students' decision making in clinical setting. Journal of Nursing Education. 2006; 45(4): 121-127. PMid:16629280

[21] Kelly C. Student's perceptions of effective clinical teaching revisited. Nurse Education Today. 2007; 27: 885-892. PMid:17321013 http://dx.doi.org/10.1016/j.nedt.2006.12.005

[22] Khan BA, Ali F, Vazir N, Barolia R, Rehan S. Students’ perceptions of clinical teaching and learning strategies: a Pakistani perspective. Nurse Education Today. 2012; 32: 85-90. PMid:21333417 http://dx.doi.org/10.1016/j.nedt.2011.01.016

[23] Larue C. Group learning strategies for nursing students: reflections on the tutor role. International Journal of Nursing Education Scholarship. 2008; 5(1): Article 30. PMid:18673298 http://dx.doi.org/10.2202/1548-923X.1604

[24] Ehrenberg AC Haggblom M. Problem-based learning in clinical nursing education: integrating theory and practice. Nurse Education in Practice. 2007; 7: 64-74. PMid:17689426 http://dx.doi.org/10.1016/j.nepr.2006.04.005

[25] Bimble M. Skills assessment using video analysis in a simulated environment: an evaluation. Pediatric Nursing. 2008; 20(7): 26-31.

[26] Prescott S, Garside J. An evaluation of simulated clinical practice for adult branch students. Nursing Standard. 2009; 23(22): 35-40. PMid:19263960

[27] Partin JL, Payne TA, Slemmons MF. Students' perceptions of their learning experiences using high-fidelity simulation to teach concepts relative to obstetrics. Nursing Education Perspectives. 2011; 32(3): 186-188. PMid:21834381 http://dx.doi.org/10.5480/1536-5026-32.3.186

[28] Ramjan LM. Contextualism adds realism: nursing students’ perceptions of and performance in numeracy skills tests. Nurse Education Today. 2011; 31: e16-e21. PMid:21126812 http://dx.doi.org/10.1016/j.nedt.2010.11.006 
[29] Dziopa, F, Ahern, K. A systematic literature review of the applications of q-technique and its methodology. Methodology. 2011; 7(2): 39-55.

[30] Barker, JH. Q-Methodology: an alternative approach to research in nurse education. Nurse Education Today. 2008; 28:917-925. PMid:18572285 http://dx.doi.org/10.1016/j.nedt.2008.05.010

[31] Brown SR. Q methodology and qualitative research. Qualitative Health Research. 1996; 6(4): 561-567. http://dx.doi.org/10.1177/104973239600600408

[32] Watts S, Stenner P: Doing Q methodology: theory, method and interpretation. Qualitative Research in Psychology. 2005 ; 2: 67-91. http://dx.doi.org/10.1191/1478088705qp022oa

[33] Parker J, Alford C. How to use Q-methodology in dream research: assumptions, procedures and benefits. Dreaming. 2010; 20 (3):169-183. http://dx.doi.org/10.1037/a0020422

[34] Akhtar-Danesh N, Baumann A, Cordingley L. Q-methodology in nursing research: a promising method for the study of subjectivity. Western Journal of Nursing Research. 2008; 30(6): 759-773. PMid:18337548 http://dx.doi.org/10.1177/0193945907312979

[35] Dennis KE. Q methodology: relevance and application to nursing research. Advances in Nursing Science. 1986; 8(3): 6-17. PMid:3083769

[36] Barbosa, JC, Willoughby, P. Rosenberg, CA, Mrtek R. Statistical methodology: VII. A structural analytic approach to medical subjectivity. Academic Emergency Medicine. 1998; 5(10): 1032-1040. PMid:9862598 http://dx.doi.org/10.1111/j.1553-2712.1998.tb02786.x

[37] Akhtar-Danesh N, Brown B, Rideout E, Brown M, Gaspar L. Use of Q-methodology to identify nursing faculty viewpoints of a collaborative BScN program experience. Nursing Leadership. 2007; 20(3): 67-85.

[38] Killam LA, Montgomery P, Luhanga, FL, Adamic P, Carter L. Views on unsafe nursing students in clinical learning. International Journal of Nursing Education Scholarship. 2010; 7(1): Article 36. PMid:21044036 http://dx.doi.org/10.2202/1548-923X.2026

[39] Brown SR, Political subjectivity: applications of Q methodology in political science. New Haven, CT: Yale University Press, 1980.

[40] Schmolck P. PQMethod. In 2.11 edition. Neubiberg: University of the Bundeswehr Munich, 2002.

[41] Benner P, Sutphen M, Leonard V, and Day L. Educating Nurses: a call for radical transformation. San Francisco: Jossey-Bass, 2010.

[42] Kermode S. Pre-clinical preparation of undergraduate nursing students. Australian Journal of Advanced Nursing. 1987; 5(1): 5-10. PMid:3440068

[43] James A, Chapman Y. Preceptors and patients - the power of two: nursing students experiences on their first acute clinical placement. Contemporary Nurse. 2009; 34(1): 34-37. http://dx.doi.org/10.5172/conu.2009.34.1.034

[44] Papp I, Markkanen M, von Bonsdorff M. Clinical environment as a learning environment: student nurses’ perceptions concerning clinical learning experiences. Nurse Education Today. 2003; 23: 262-268. http://dx.doi.org/10.1016/S0260-6917(02)00185-5

[45] Smedley A. The self-directed learning readiness of first year bachelor of nursing students. Journal of Research in Nursing. 2007; 12(4): 373-385. http://dx.doi.org/10.1177/1744987107077532

[46] Bevis O. Watson J. Towards a caring curriculum: a new pedagogy for nursing. Sudbury, MA: Jones and Bartlett, 2000.

[47] Dyjur L, Rankin J, Lane A. Maths for medications: an analytical exemplar of the social organization of nurses’ knowledge. Nursing Philosophy. 2011; 12: 200-213. PMid:21668619 http://dx.doi.org/10.1111/j.1466-769X.2011.00493.x

[48] Ironside PM. A student's experience learning to think. Nursing and Health Care Perspectives. 1999; 20(5): 238-242. PMid:10754845

[49] Sherwood G, Drenkard K. Quality and safety curricula in nursing education: matching practice realities. Nursing Outlook. 2007; 55: 151-155. PMid:17524803 http://dx.doi.org/10.1016/j.outlook.2007.02.004

[50] Day L, Smith EL, Integrating quality and safety content into clinical teaching in the acute care setting. Nursing Outlook. 2007; 55: 138-143. PMid:17524801 http://dx.doi.org/10.1016/j.outlook.2007.03.002

[51] Smith EL, Cronenwett L, Sherwood G. Current assessments of quality and safety education in nursing. Nursing Outlook. 2007; 55: 132-137. PMid:17524800 http://dx.doi.org/10.1016/j.outlook.2007.02.005

[52] Dekker S. Patient Safety: a human factors approach. Boca Raton, Florida: CRC Press, 2011. http://dx.doi.org/10.1201/b10942 